Check for updates

Cite this: RSC Adv., 2018, 8, 15087

Received 1st March 2018

Accepted 13th April 2018

DOI: $10.1039 / \mathrm{c} 8 \mathrm{ra01805g}$

rsc.li/rsc-advances

\section{Efficient removal of hexavalent chromium from water by an adsorption-reduction mechanism with sandwiched nanocomposites $\dagger$}

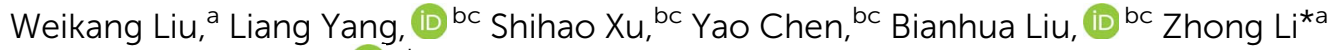 \\ and Changlong Jiang (iD *bc
}

Hexavalent chromium $\mathrm{Cr}(\mathrm{vl})$, one of the most toxic contaminants, is released in the environment due to various anthropogenic activities. This study presents a novel sandwiched nanocomposite synthesized using graphene oxide $(\mathrm{GO})$, manganese dioxide $\left(\mathrm{MnO}_{2}\right)$ nanowires, iron oxide $\left(\mathrm{Fe}_{3} \mathrm{O}_{4}\right)$ nanoparticles and polypyrrole (PPy) to remove hexavalent chromium ion $\mathrm{Cr}(\mathrm{VI})$ from water by an adsorption-reduction mechanism. In the sandwiched nanocomposites, GO provided enough surface area, functional groups, and hydrophilic surface for efficient absorption. $\mathrm{Fe}_{3} \mathrm{O}_{4}$ nanoparticles with excellent magnetic properties make it easy to separate and recover from water. Under acidic conditions, $\mathrm{MnO}_{2}$ nanowires act as both template and oxidant to initiate the polymerization of pyrrole monomers on its freshly activated surface to obtain $\mathrm{GO} / \mathrm{MnO}_{2} / \mathrm{Fe}_{3} \mathrm{O}_{4} / \mathrm{PPy}$ (designated as GMFP) nanocomposite. GMFP could effectively adsorb $\mathrm{Cr}(\mathrm{VI})$ through electrostatic attraction, and the adsorbed $\mathrm{Cr}(\mathrm{VI})$ ions were partly reduced to trivalent chromium $\mathrm{Cr}(\mathrm{III})(62 \%)$, resulting in the efficient adsorption and high removal of $\mathrm{Cr}(\mathrm{VI})$ from water. Hexavalent chromium adsorption by GMFP is strongly $\mathrm{pH}$ dependent and the adsorption kinetics followed the pseudo-second-order model. The Langmuir isothermal model described the adsorption isotherm data well and the maximum adsorption capacity was up to $374.53 \mathrm{mg} \mathrm{g}^{-1}$ at $\mathrm{pH} 2.0$. These experimental results suggested that GMFP had great potential as an economic and efficient adsorbent of hexavalent chromium from wastewater, which has huge application potential.

\section{Introduction}

The existence of heavy metal ions, such as $\mathrm{Pb}$ (II), $\mathrm{Fe}(\mathrm{III}), \mathrm{Hg}$ (II), $\mathrm{Cu}$ (II) and $\mathrm{Cr}(\mathrm{VI})$ in groundwater is one of the most serious environmental problems today., ${ }^{1,2}$ These toxic contaminants are a serious danger to human health. They enter the ecosystem through industrial and agricultural processes as well as mining activities. ${ }^{3,4}$ Among the toxic metal ions, chromium is a common contaminant in the environment coming from various anthropogenic activities, including metal electroplating, steelworks manufacturing, leather tanning, synthesis of pigments and so on. It is found that chromium exists in the environment in two stable states: trivalent $\mathrm{Cr}(\mathrm{III})$ and hexavalent $\mathrm{Cr}(\mathrm{VI})$, and the toxicity of the hexavalent form is five hundred times greater than that of the trivalent form. ${ }^{5} \mathrm{Cr}(\mathrm{vI})$ can cause many health problems, such as

${ }^{a}$ School of Chemical Engineering, Anhui University of Science and Technology, Huainan, Anhui, 232001, China. E-mail: zhongli@aust.edu.cn

${ }^{b}$ Institute of Intelligent Machines, Chinese Academy of Sciences, Hefei, Anhui, 230031, China.E-mail: cljiang@iim.ac.cn

${ }^{c}$ State Key Laboratory of Transducer Technology, Chinese Academy of Sciences, Hefei, Anhui, 230031, China

$\uparrow$ Electronic supplementary information (ESI) available. See DOI: 10.1039/c8ra01805g liver damage, pulmonary congestion, asthma, and severe diarrhea. ${ }^{1,5}$ Therefore, various agencies such as WHO and USEPA have given a tolerable limit of $0.05 \mathrm{mg} \mathrm{L}^{-1}$ for dissolved $\mathrm{Cr}(\mathrm{vI})$ in drinking water, and that for total chromium (all form of chromium) is $2 \mathrm{mg} \mathrm{L}^{-1} .^{6}$ Therefore, it is very urgent to remove $\mathrm{Cr}(\mathrm{vI})$ from wastewater or reduce $\mathrm{Cr}(\mathrm{vI})$ to less toxic $\mathrm{Cr}(\mathrm{III})$ prior to discharge into the environment. Until now, several methods have been reported to reduce the harmful effects of $\mathrm{Cr}(\mathrm{vI})$ such as electrical enrichment, reverse osmosis, ion exchange and adsorption..$^{7-10}$ Owing to the simple procedure, cost-effective, and high efficiency, adsorption methods have great potential for the removal of $\mathrm{Cr}(\mathrm{vI})$ and thus attracting more and more attention in recent years. ${ }^{11}$

Different types of adsorbent materials have been widely used for the removal of $\mathrm{Cr}(\mathrm{vI})$ from wastewater. However, conventional adsorbents often show a limited adsorption capacity or not easily separated even cause potential secondary pollution because they do not have enough surface area, functional groups, and hydrophilic surface. ${ }^{\mathbf{1 2}}$ Therefore, it is important to fabricate a nanomaterials with excellent performances of adsorption, reduction, and collectability simultaneously for the removal of $\mathrm{Cr}(\mathrm{vI})$ from wastewater.

Among the various materials, graphene oxide (GO), a twodimensional carbon nanomaterial, has been used as a highly 
efficient adsorbent to remove heavy metal ions because of having an ultralarge specific surface area and abundant oxygencontaining groups (e.g. $-\mathrm{OH}$ and $-\mathrm{COOH}) .{ }^{13-16}$ And the idea of GO coated with $\mathrm{MnO}_{2}$ may be utilized in synthesizing new nanocomposite materials which would have better performances in metal ions adsorption applications. Polypyrrole (PPy) carries large amounts of positively charged nitrogen atoms in the polymer chains, which render it a good prospect in adsorption application. ${ }^{17-19}$ Although GO/ $\mathrm{MnO}_{2} / \mathrm{PPy}$ has high adsorption and reduction abilities for $\mathrm{Cr}(\mathrm{VI})$, the resulting mixture could not be easily collected from water after treatment towards $\mathrm{Cr}(\mathrm{vI}) .{ }^{20}$ Herein, $\mathrm{Fe}_{3} \mathrm{O}_{4}$ was incorporated with $\mathrm{GO} /$ $\mathrm{MnO}_{2} / \mathrm{PPy}$ to obtain $\mathrm{GO} / \mathrm{MnO}_{2} / \mathrm{Fe}_{3} \mathrm{O}_{4} / \mathrm{PPy}$, which displayed a high removal ability on $\mathrm{Cr}(\mathrm{VI})$ through adsorption and reduction, and an excellent magnetic collectability from aqueous solution. The optimal condition and the removal mechanism were investigated. This work provides a facile, efficient, and environmentally-friendly approach for the remediation of $\mathrm{Cr}(\mathrm{vI})$ contaminated wastewater.

\section{Results and discussion}

\subsection{Characterization}

Aim to design materials with high adsorption capacity for the chromium removal, a sandwiched nanocomposite has been developed with utilizing graphene oxide (GO), manganese dioxide $\left(\mathrm{MnO}_{2}\right)$ nanowires, iron oxide $\left(\mathrm{Fe}_{3} \mathrm{O}_{4}\right)$ nanoparticles and polypyrrole (PPy), as illustrated in Scheme 1. In this study, we employed GO as the substrate for its ultralarge specific surface area and abundant oxygen-containing groups. By means of hydrothermal method, the $\mathrm{MnO}_{2}$ nanowires were deposited at the surface of graphene oxide sheets. $\mathrm{Fe}_{3} \mathrm{O}_{4}$ was incorporated with $\mathrm{GO} / \mathrm{MnO}_{2}$ to obtain $\mathrm{GO} / \mathrm{MnO}_{2} / \mathrm{Fe}_{3} \mathrm{O}_{4}$, which displayed an excellent magnetic collectability as adsorbent for $\mathrm{Cr}(\mathrm{vI})$ remove from aqueous solution. Finally, by using pre-prepared $\mathrm{MnO}_{2}$ nanowires as the reactive templates, pyrrole monomers transport to the surface of $\mathrm{MnO}_{2}$ nanowires, leading to the formation of $\mathrm{GO} / \mathrm{MnO}_{2} / \mathrm{Fe}_{3} \mathrm{O}_{4} / \mathrm{PPy}$, which displayed a high removal ability on $\mathrm{Cr}(\mathrm{vI})$ through adsorption and reduction.

The obtained GMFP nanocomposite was first characterized by scanning electron microscopy (SEM) (Fig. 1). GO was prepared by modified Hummers method from natural flake graphite (Fig. 1A). Then $\mathrm{GO} / \mathrm{MnO}_{2}$ nanomaterials were fabricated via hydro-thermal method. As shown in Fig. $1 \mathrm{~B}$, the $\mathrm{MnO}_{2}$ component in the composite is nanowire, which is several hundred nanometers to several micrometers in length and homo-geneously and densely attached on the surface of graphene sheets. Fig. $1 \mathrm{C}$ is the $\mathrm{GO} / \mathrm{MnO}_{2} / \mathrm{Fe}_{3} \mathrm{O}_{4}$ nanocomposites, in which the $\mathrm{Fe}_{3} \mathrm{O}_{4}$ nanoparticles were well distributed on the surface of $\mathrm{GO} / \mathrm{MnO}_{2}$ nanocomposites. After functionalized with pyrrole, as displayed in Fig. 1D, the resulting sample has rough surface. $\mathrm{MnO}_{2}$ is a strong oxidant and acts as chemical oxidative initiator for pyrrole polymerization. Since the $\mathrm{MnO}_{2}$ serves as oxidant and template in the chemical reaction, PPy shell is coated on $\mathrm{MnO}_{2}$ nanowires to form core-shell structure.

The formation mechanism of $\mathrm{MnO}_{2} / \mathrm{PPy}$ coaxial nanowires is illustrated in Scheme 2. It is understandable that the core of the coaxial nanowires is $\alpha-\mathrm{MnO}_{2}$ and the shell is PPy. In our case, the $\alpha-\mathrm{MnO}_{2}$ nanowire surface exposed in acidic solution contacts with pyrrole monomers to proceed with a redox reaction. When $\mathrm{H}^{+}$ions are added in the solution, some of them are adsorbed on the surface of $\alpha-\mathrm{MnO}_{2}$ nanowires due to the electrostatic attraction. After adding pyrrole, the monomers transport to the surface of $\alpha-\mathrm{MnO}_{2}$ nanowires because of their intrinsic hydrophilic characteristic in acid solution and polymerize over there, leading to the formation of PPy shell. Fig. 2 shows the TEM images of $\alpha-\mathrm{MnO}_{2}$ nanowires and $\mathrm{MnO}_{2} / \mathrm{PPy}$ coaxial nanowires. As shown in Fig. 2A, the $\mathrm{MnO}_{2}$ sample demonstrates 1-D nanostructured crystals, no other morphologies are observed in the sample. TEM image in Fig. 2C further confirms the formation of $\mathrm{MnO}_{2}$ nanowires with average thickness of $22.52 \mathrm{~nm}$ and average length of several microns. Fig. 2B shows the TEM images of $\mathrm{MnO}_{2} / \mathrm{PPy}$ coaxial nanowires, the average thickness of the $\mathrm{MnO}_{2} / \mathrm{PPy}$ coaxial nanowires was $49.38 \mathrm{~nm}$. So the average thickness has changed greatly before and after the treatment of PPy. TEM image in Fig. 2D clearly reveals the core/shell morphology of the $\mathrm{MnO}_{2} / \mathrm{PPy}$ nanowires with the outer layer of PPy with thickness about 5-10 nm and the inner layer of $\mathrm{MnO}_{2}$ nanowires with the wall thinned, confirming the successful preparation of $\mathrm{MnO}_{2} / \mathrm{PPy}$ coaxial nanowires. The image of size distribution was shown in Fig. S1. $\dagger$

The crystal structure of the GMFP nanocomposite has been identified by X-ray power diffraction measurement. It can be clearly seen that diffraction peaks located at $2 \theta=12.8,18.1$, 28.7, 36.5, 37.5, 42.0, 49.8, 56.1, 60.1, 65.6 and $69.5^{\circ}$, which can be assigned to the (110), (200), (310), (400), (211), (301), (411), (600), (521), (002) and (541) planes of $\alpha-\mathrm{MnO}_{2}$ (JCPDS no. 440141) (Fig. 3a)..$^{\mathbf{2 1 , 2 2}}$ No characteristic impurity peaks are
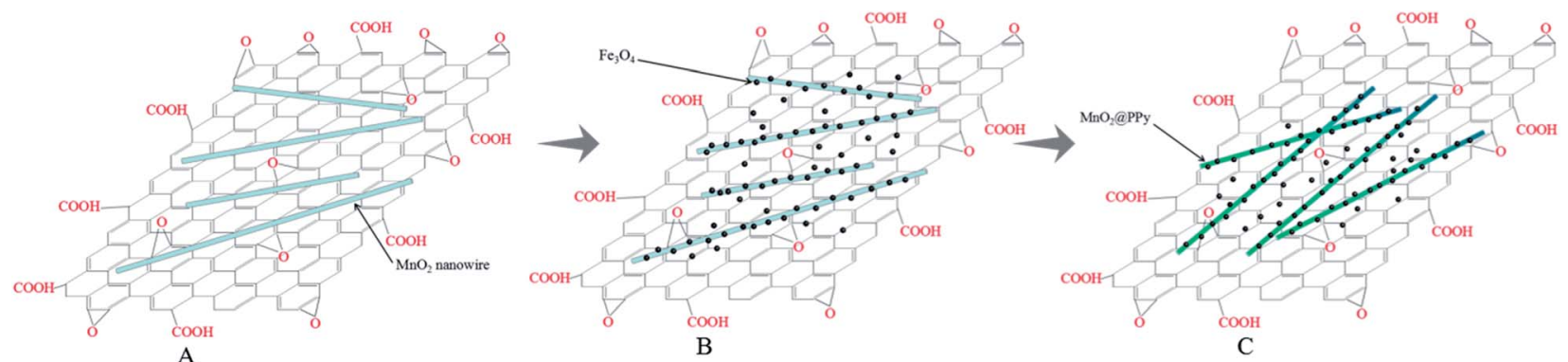

Scheme 1 Schematic illustration of the formation mechanism of (A) $\mathrm{GO} / \mathrm{MnO}_{2}$, (B) $\mathrm{GO} / \mathrm{MnO}_{2} / \mathrm{Fe}_{3} \mathrm{O}_{4},(\mathrm{C}) \mathrm{GO} / \mathrm{MnO}_{2} / \mathrm{Fe}_{3} \mathrm{O}_{4} / \mathrm{PPy}$. 


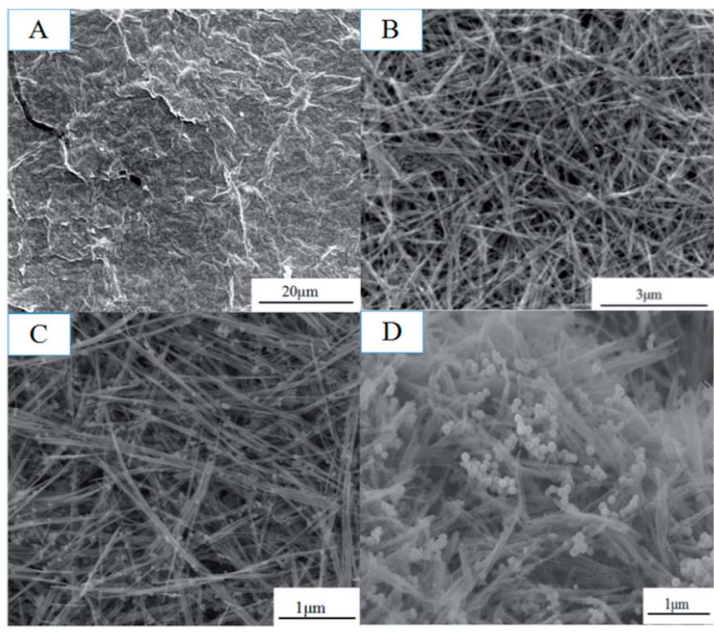

Fig. 1 SEM images of (A) $\mathrm{GO}$, (B) $\mathrm{GO} / \mathrm{MnO}_{2}$, (C) $\mathrm{GO} / \mathrm{MnO}_{2} / \mathrm{Fe}_{3} \mathrm{O}_{4}$, and (D) GMFP nanocomposites.

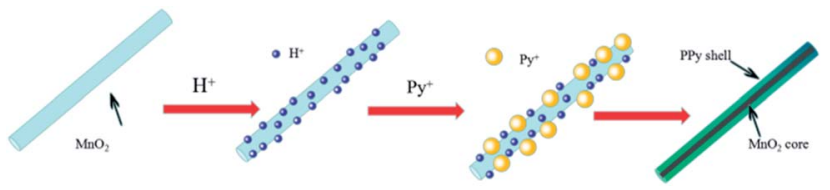

Scheme 2 Schematic illustration of the formation mechanism of the $\mathrm{MnO}_{2} / \mathrm{PPy}$ nanocomposites in acid condition.

observed, indicating the high purity of $\alpha-\mathrm{MnO}_{2}$ nanowires. And seen from the XRD pattern of the $\mathrm{MnO}_{2} / \mathrm{PPy}$ in Fig. 3b, all diffraction peaks are similar to the pristine $\alpha-\mathrm{MnO}_{2}$, confirming the presence of $\alpha-\mathrm{MnO}_{2}$ in the composites after in situ polymerization. As shown in Fig. 3 d, the diffraction peaks $(2 \theta=$ $30.3^{\circ}, 35.62^{\circ}, 43.3^{\circ}, 53.34^{\circ}, 57.16^{\circ}$, and $62.76^{\circ}$ ) of $\mathrm{Fe}_{3} \mathrm{O}_{4}$ (JCPDS no. 75-0033) appeared in the XRD pattern of GMFP, suggesting that $\mathrm{Fe}_{3} \mathrm{O}_{4}$ was successfully combined with $\mathrm{GO} / \mathrm{MnO}_{2}{ }^{23}$

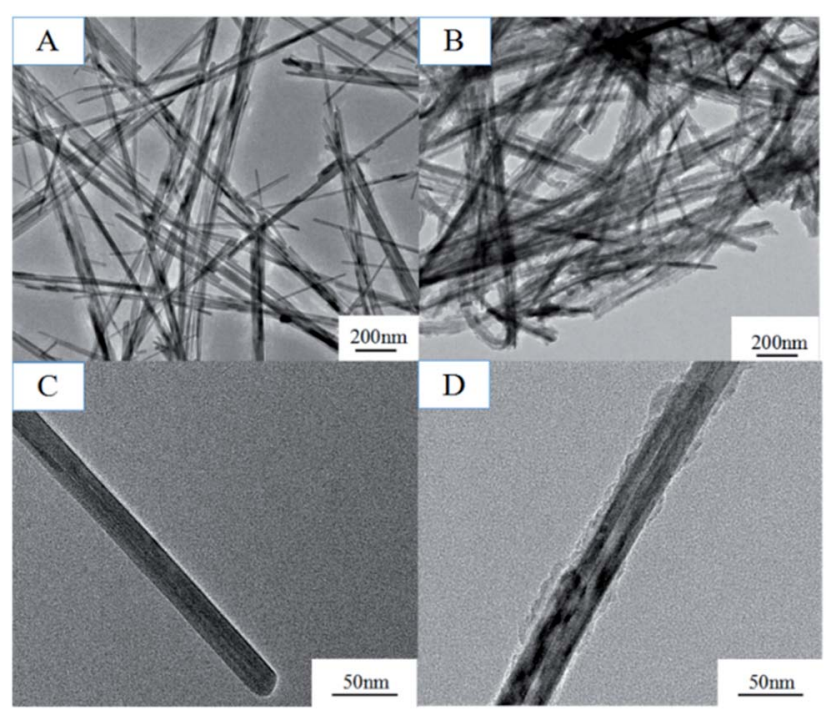

Fig. 2 TEM images of (A) and (C) $\mathrm{MnO}_{2}$, (B) and (D) $\mathrm{MnO}_{2} / \mathrm{PPy}$.

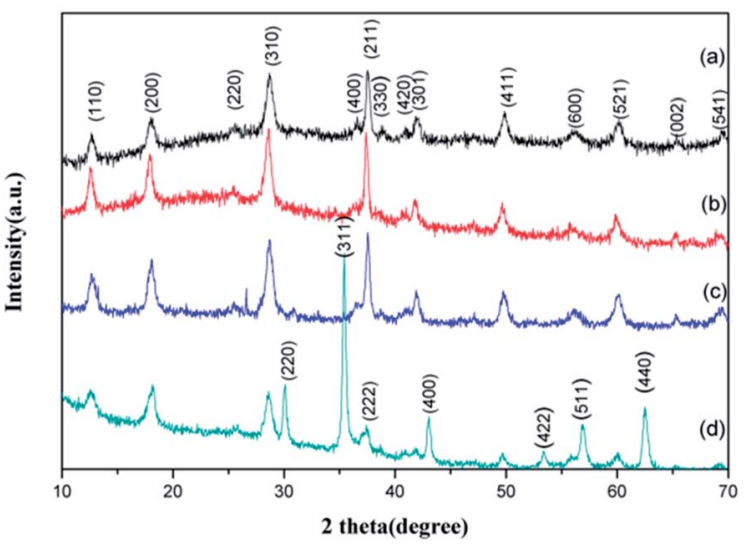

Fig. 3 X-ray diffraction patterns of (a) $\mathrm{MnO}_{2}$, (b) $\mathrm{MnO}_{2} / \mathrm{PPy}$, (c) GO/ $\mathrm{MnO}_{2}$, (d) GMFP.

The structural information and chemical component of are also identified by the FT-IR spectroscopy. For comparison, the spectra for both $\alpha-\mathrm{MnO}_{2}$ and $\mathrm{MnO}_{2} / \mathrm{PPy}$ coaxial nanowires are recorded and shown in Fig. 4. It can be seen that from Fig. 4a, the characteristic peaks of $\alpha-\mathrm{MnO}_{2}$ appear at about 721, 531 and $475 \mathrm{~cm}^{-1}$, belonging to $\mathrm{Mn}-\mathrm{O}$ vibrations of $\mathrm{MnO}_{6}$ octahedra in $\alpha-\mathrm{MnO}_{2}$ nanowires, and at $1635 \mathrm{~cm}^{-1}$, relating to $\mathrm{O}-\mathrm{H}$ vibrational mode of absorbed water. By contrast, in the spectrum of $\mathrm{MnO}_{2} / \mathrm{PPy}$ coaxial nanowires (Fig. 4b), the aforesaid peaks at 531 and $475 \mathrm{~cm}^{-1}$ shift to 527 and $469 \mathrm{~cm}^{-1}$, respectively, and all display attenuation in intensity, reflecting a mutual interaction between PPy and $\mathrm{MnO}_{2}$ that, most likely, is a hydrogen bond formed between oxygen atom of $\mathrm{Mn}-\mathrm{O}$ and hydrogen atom of $\mathrm{N}-\mathrm{H}$ in PPy. ${ }^{24}$ Such spectral information suggests that the PPy shell has been coated closely on $\mathrm{MnO}_{2}$ surface and in doping state. In Fig. $4 \mathrm{c}$ and a characteristic peak at $586 \mathrm{~cm}^{-1}$ for the $\mathrm{Fe}-\mathrm{O}$ stretching vibration of $\mathrm{Fe}_{3} \mathrm{O}_{4}$ appeared. While the transmissions around 1626 and $874 \mathrm{~cm}^{-1}$ in Fig. $4 \mathrm{c}$ from the amine-functionalized nanocrystals matched well with that from free 1,6-hexa-diamine, indicating the existence of the free $-\mathrm{NH}_{2}$ group on the amine-functionalized $\mathrm{Fe}_{3} \mathrm{O}_{4}$ nano-materials.

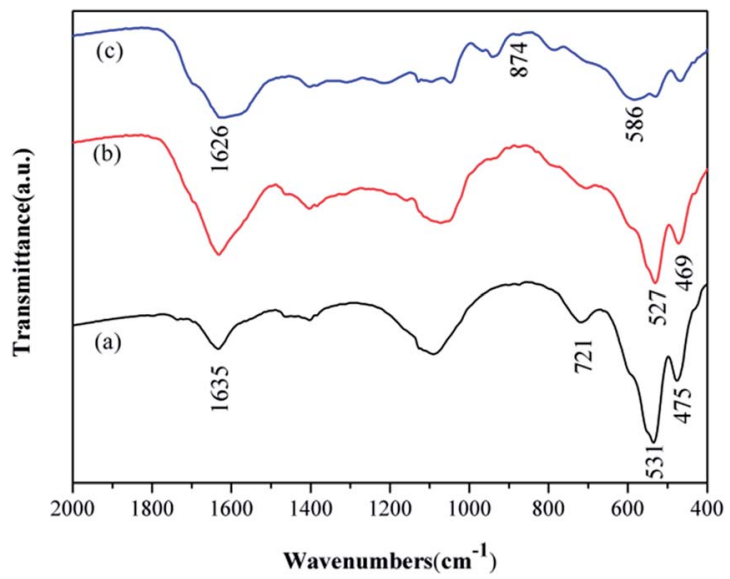

Fig. 4 FT-IR spectra of (a) $\mathrm{MnO}_{2}$, (b) $\mathrm{MnO}_{2} / \mathrm{PPy}$, (c) GMFP nanocomposites. 


\subsection{Determination of $\mathrm{Cr}^{6+}$ concentration}

The concentration of $\mathrm{Cr}^{6+}$ was analyzed by UV spectrophotometric method, ${ }^{25}$ and the results were shown in Fig. S2 and S3 (ESI $\dagger$ ). When absorbance is plotted against concentration, the data are regressed linearly, so we could calculate concentration of hexavalent chromium ion from the absorbance.

\subsection{Effect of solution $\mathrm{pH}$}

The solution $\mathrm{pH}$ has been acknowledged as the most important factor governing metal adsorption onto the adsorbent. ${ }^{26}$ To investigate the adsorption capacity of GMFP under both acidic and alkalic conditions, $\mathrm{pH}$ values from 2 to 12 at initial concentrations of $300 \mathrm{mg} \mathrm{L}^{-1}$ to evaluate the effect of $\mathrm{pH}$ on the $\mathrm{Cr}^{6+}$ adsorption process.

Solution $\mathrm{pH}$ affects both the surface charge of an adsorbent and the speciation of metal ions. The effect of initial solution $\mathrm{pH}$ on $\mathrm{Cr}(\mathrm{vI})$ adsorption by the GMFP composite was therefore studied and illustrated in Fig. 5. As shown in Fig. 5A, the $\mathrm{Cr}(\mathrm{vI})$ adsorption capacity decreased as the solution $\mathrm{pH}$ increasing from 2 to 12 . $\mathrm{Cr}(\mathrm{vI})$ speciation in solution is known to be highly $\mathrm{pH}$ dependent (Fig. 5B). Chromic acid $\left(\mathrm{H}_{2} \mathrm{CrO}_{4}\right)$ occurs when $\mathrm{pH}$ is less than 1. Furthermore, from acidic $\mathrm{pH} 1$ to the neutral $\mathrm{pH} 7$, the hydrogen chromate ion $\left(\mathrm{HCrO}_{4}{ }^{-}\right)$exist, whereas, above the neutral $\mathrm{pH}$, only chromate ions $\left(\mathrm{CrO}_{4}{ }^{2-}\right)$ exist in the solution. ${ }^{27,28}$ At a lower $\mathrm{pH}$, the adsorption effect is high because predominant
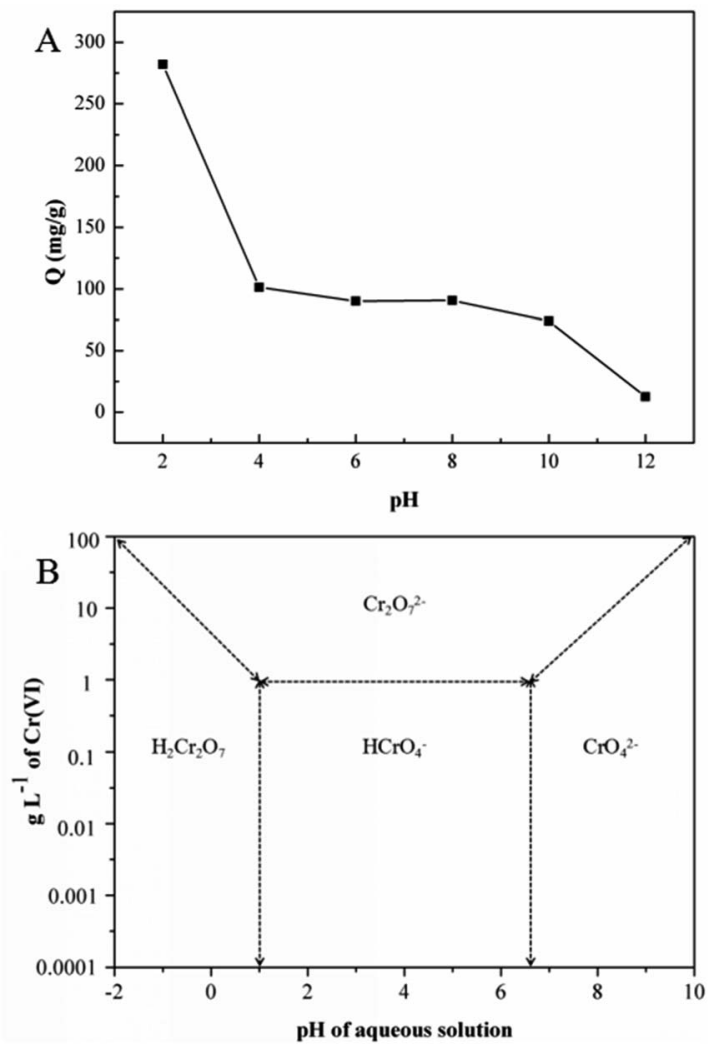

Fig. 5 (A) Effect of $\mathrm{pH}$ on the adsorption of $\mathrm{Cr}(\mathrm{vI})$ by GMFP: temperature, $298.15 \mathrm{~K}$; adsorption time, $6 \mathrm{~h}$; and initial $\mathrm{Cr}(\mathrm{VI})$ concentration, $300 \mathrm{mg} \mathrm{L}^{-1}$, (B) relative distribution of $\mathrm{Cr}(\mathrm{vl})$ species in water as a function of $\mathrm{pH}$ and $\mathrm{Cr}(\mathrm{vI})$ concentration (adapted from ref. 1).
$\mathrm{Cr}^{6+}$ species mainly exists in monovalent $\mathrm{HCrO}_{4}{ }^{-}$form, which is then gradually converted to divalent $\mathrm{CrO}_{4}{ }^{2-}$ and $\mathrm{Cr}_{2} \mathrm{O}_{7}{ }^{2-}$ as $\mathrm{pH}$ increases. The adsorption free energy of $\mathrm{HCrO}_{4}{ }^{-}$is lower than that of $\mathrm{CrO}_{4}{ }^{2-}$ and $\mathrm{Cr}_{2} \mathrm{O}_{7}{ }^{2-}$; and consequently, $\mathrm{HCrO}_{4}{ }^{-}$is more favorably adsorbed than $\mathrm{CrO}_{4}{ }^{2-}$ and $\mathrm{Cr}_{2} \mathrm{O}_{7}{ }^{2-}$ at the same concentration. As the $\mathrm{pH}$ increases, the GMFP nanocomposites surface becomes increasingly deprotonated so that the amount of positive surface charges is significantly decreased, leading to a reduction in the adsorption capacity of $\mathrm{Cr}^{6+}$. Thus, the adsorption quantities of $\mathrm{Cr}^{6+}$ at a lower $\mathrm{pH}$ are larger than that of at higher $\mathrm{pH}$. The controlled experiments about without use of adsorbent in the presence of acid and without acid only use adsorbent have been made. The result was shown in Fig. S4. $\dagger$ The figure shows that the concentration of $\mathrm{Cr}(\mathrm{vI})$ does not change without use of adsorbent in the presence of acid $(\mathrm{pH}=2)$, and the $\mathrm{Cr}(\mathrm{vI})$ percentage removal is about $26 \%$ without acid only use the adsorbent. This result shows that the $\mathrm{pH}$ value is an important factor affecting the adsorption efficiency.

\subsection{Adsorption isotherms}

Batch equilibrium adsorption experiments were used for adsorption assessment through plots of adsorption isotherms. The maximum adsorption capacity can be obtained from adsorption isotherms. Adsorption isotherm consists of two important parameters, Langmuir and Freundlich isotherms.

Langmuir adsorption isotherms have been successfully applied to many real adsorption processes. A basic assumption of Langmuir theory is that adsorption takes place at specific homogeneous sites within the adsorbent. It is assumed that once a molecule occupies a site, no further adsorption can occur at that site. Theoretically, a saturation value is reached and no further sorption can occur. A linear form of this expression is:

$$
\frac{C_{\mathrm{e}}}{q_{\mathrm{e}}}=\frac{1}{b q_{\mathrm{m}}}+\frac{C_{\mathrm{e}}}{q_{\mathrm{m}}}
$$

where $q_{\mathrm{e}}\left(\mathrm{mg} \mathrm{g}^{-1}\right)$ is the amount of solution adsorbed per unit mass of the adsorbent, $C_{\mathrm{e}}\left(\mathrm{mg} \mathrm{L}^{-1}\right)$ is the solute equilibrium concentration, $q_{\mathrm{m}}\left(\mathrm{mg} \mathrm{g}^{-1}\right)$ is the maximum adsorbate amount that forms a complete monolayer on the surface, and $b\left(\mathrm{~L} \mathrm{mg}^{-1}\right)$ is the Langmuir constant related to adsorption heat. When $C_{\mathrm{e}} / q_{\mathrm{e}}$ is plotted against $C_{\mathrm{e}}$ and the data are regressed linearly, the $q_{\mathrm{m}}$ and $b$ constants can be calculated from the slope and the intercept.

The values of these parameters, as analyzed from the plots shown in Fig. 6, are summarized in Table 1. According to the obtained results, the adsorption data of the $\mathrm{Cr}(\mathrm{vI})$ ions of GMFP nanocomposites were fitted particularly well with the Langmuir model, with good correlation coefficients. The maximal adsorption capacity of $\mathrm{Cr}(\mathrm{vI})$ ions of GMFP nano-composites was about $374.53 \mathrm{mg} \mathrm{g}^{-1}$. By comparison to the reported adsorbents (Table 2), GMFP has a superb removal capacity toward $\mathrm{Cr}(\mathrm{vI})$. Therefore, GMFP is a potential material for Cr-contaminated wastewater cleanup.

\subsection{Adsorption kinetics}

Adsorption kinetics, demonstrating the solute uptake rate, is one of the most important factors which represent the 


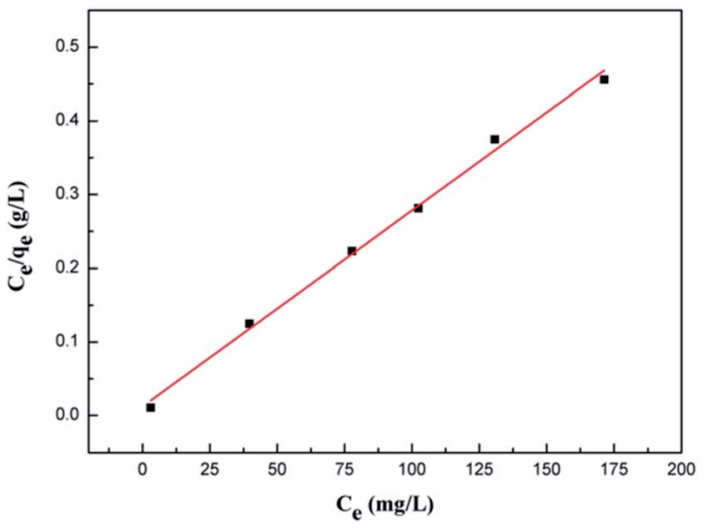

Fig. 6 Fit of equilibrium data to Langmuir isotherm model.

Table 1 Parameters of the Langmuir isotherms for $\mathrm{Cr}^{6+}$ adsorption onto GMFP nanocomposites

\begin{tabular}{lllll}
\hline $\mathrm{pH}$ & $T(\mathrm{~K})$ & $q_{\mathrm{m}}\left(\mathrm{mg} \mathrm{g}^{-1}\right)$ & $b$ & $R^{2}$ \\
\hline 2 & 308.5 & 374.53 & 0.320 & 0.995
\end{tabular}

adsorption efficiency of the GMFP and therefore, determines their potential applications. The effect of adsorption time on the adsorption capacity at different initial solution concentrations is shown in Fig. 7A. The removal of $\mathrm{Cr}^{6+}$ increases with increasing contact time. To better understand the adsorption behaviors, the kinetic adsorption data were simulated with the pseudo-second-order rate equation, which are expressed as follows:

$$
\frac{t}{q_{t}}=\frac{1}{k_{2} q_{\mathrm{e}}{ }^{2}}+\frac{t}{q_{\mathrm{e}}}
$$

where $q_{\mathrm{e}}$ and $q_{t}\left(\mathrm{mg} \mathrm{g}^{-1}\right)$ are the adsorption capacities at equilibrium and at time $t(\mathrm{~min}), k_{2}\left(\mathrm{~g} \mathrm{mg}^{-1} \mathrm{~min}^{-1}\right)$ are the pseudosecond-order rate adsorption constants.

The values of these parameters, as analyzed from the plots shown in Fig. 7, are summarized in Table 3. It is found that the removal of $\mathrm{Cr}^{6+}$ increases with increasing contact time. The equilibrium capacity $q_{\mathrm{e}}$ calculated from the pseudo-secondorder kinetic model were $261.78,316.45,350.87$ and $364.96 \mathrm{mg} \mathrm{g}^{-1}$ for the 150, 200, 250 and $300 \mathrm{mg} \mathrm{L}^{-1}$ initial $\mathrm{Cr}^{6+}$

Table 2 Comparison of maximum adsorption capacity of $\mathrm{Cr}(\mathrm{VI})$ on GMFP with other adsorbents

\begin{tabular}{llll}
\hline Absorbent & $Q_{\mathrm{m}}\left(\mathrm{mg} \mathrm{g}^{-1}\right)$ & Optimum pH & Ref. \\
\hline Graphene oxide & 65.2 & 2 & 29 \\
$\mathrm{GO} / \mathrm{MnO}_{2} / \mathrm{Fe}_{3} \mathrm{O}_{4}$ & 193.1 & 2 & 5 \\
$\mathrm{MnO}_{2} / \mathrm{Fe}_{3} \mathrm{O}_{4} / \mathrm{o}-\mathrm{MWCNTs}$ & 186.9 & 2 & 30 \\
$\mathrm{PPy}_{\text {nanoclusters }}$ & 180.4 & 5 & 31 \\
$\mathrm{PPy} / \mathrm{Fe}_{3} \mathrm{O}_{4}$ & 169.4 & 2 & 32 \\
PPy/o-MWCNTs & 294.1 & 2 & 33 \\
PPy/2,5-Diaminobenzene & 222.2 & 2 & 34 \\
PPy/sepiolite nanofibers & 302 & 2 & 35 \\
GO/MnO $/ \mathrm{Mn}_{2} \mathrm{O}_{4} /$ PPy & 374.5 & 2 & This study
\end{tabular}
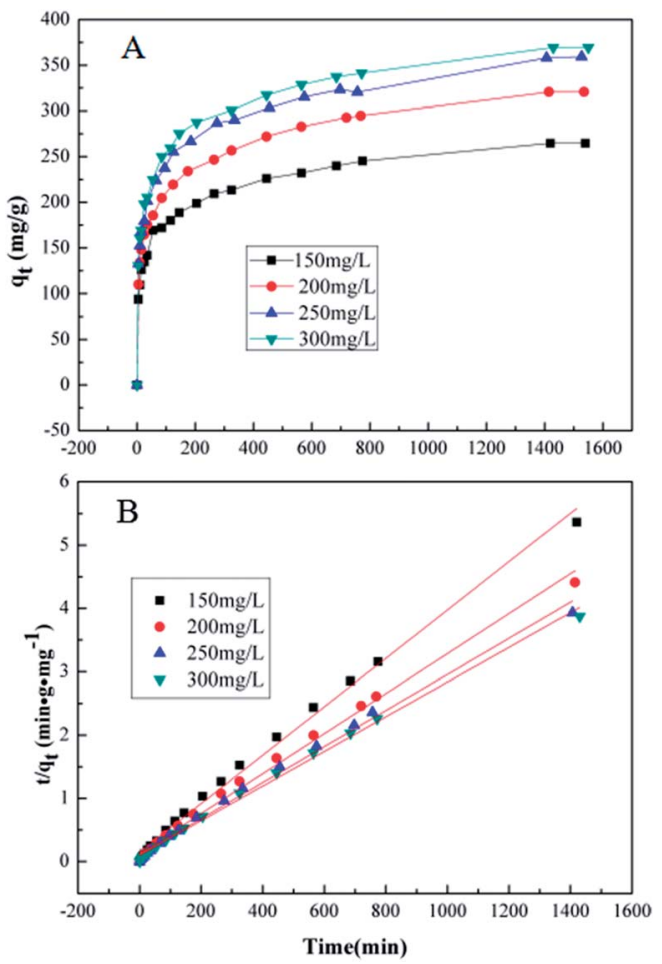

Fig. 7 (A) The adsorption capacity of GMFP nano-composites for different concentrations of $\mathrm{Cr}(\mathrm{VI})$ ions with time. (B) The pseudosecond-order model for adsorption of $\mathrm{Cr}(\mathrm{VI})$ ions by GMFP nanocomposites.

solution. The rate constants $\left(k_{2}\right)$ were very small, suggesting that the adsorption process was not very fast. Fig. 7B and Table 3 show the pseudo-second-order model for adsorption of $\mathrm{Cr}(\mathrm{vI})$ by GMFP nanocomposites. From the plots $t / q_{t} v s$. $T$ of GMFP nanocomposites adsorbent at initial concentrations of $\mathrm{Cr}(\mathrm{VI})$ varied from 150 to $300 \mathrm{mg} \mathrm{L}^{-1}$, the pseudo-second-order rate constant $\left(k_{2}\right)$ decreases from $9.588 \times 10^{-5}$ to $7.396 \times 10^{-5} \mathrm{~g}$ $\mathrm{mg}^{-1} \min ^{-1}$. The calculated $q_{\mathrm{e}}$ is also close to the theoretical one, and the correlation coefficient $\left(R^{2}\right)$ is above 0.994. This result indicates that the adsorption kinetics of the $\operatorname{Cr}(\mathrm{vI})$ removal by the GMFP nanocomposites follows the pseudosecond-order model, suggesting it is a chemisorption process.

\subsection{Mechanisms of adsorption}

We also use the XPS spectra to investigate the mechanism of $\mathrm{Cr}(\mathrm{vI})$ adsorption with the GMFP nanomaterials in current system (see Fig. S5 $\dagger$ ). The presence of the elements C, N, O, Mn and Fe with

Table 3 Kinetics parameters for $\mathrm{Cr}(\mathrm{VI})$ adsorption onto GMFP nanocomposites with different concentrations

\begin{tabular}{llll}
$\begin{array}{l}\text { Concentration of } \\
\mathrm{Cr}(\mathrm{vI}) \text { ions }\left(\mathrm{mg} \mathrm{L}^{-1}\right)\end{array}$ & $q_{\mathrm{e}}\left(\mathrm{mg} \mathrm{g}^{-1}\right)$ & $k_{2}\left(\mathrm{~g} \mathrm{mg}^{-1} \mathrm{~min}^{-1}\right)$ & $R^{2}$ \\
\hline 150 & 261.78 & $9.588 \times 10^{-5}$ & 0.9943 \\
200 & 316.45 & $7.856 \times 10^{-5}$ & 0.9941 \\
250 & 350.87 & $7.454 \times 10^{-5}$ & 0.9936 \\
300 & 364.96 & $7.396 \times 10^{-5}$ & 0.9955
\end{tabular}


high contents in the GMFP was evidenced by the photoelectron lines of the wide-scan XPS spectrum at 285, 401, 532, 641 and $711 \mathrm{eV}$, attributed to $\mathrm{C} 1 \mathrm{~s}, \mathrm{~N} 1 \mathrm{~s}, \mathrm{O} 1 \mathrm{~s}, \mathrm{Mn} 2 \mathrm{p}$ and Fe 2p, respectively (Fig. S5A $\dagger$ ). The Mn 2p XPS spectrum exhibits two characteristic peaks at 642.0 and $653.5 \mathrm{eV}$, corresponding to the $\mathrm{Mn} 2 \mathrm{p}_{3 / 2}$ and Mn $2 \mathrm{p}_{1 / 2}$ spin-orbit peaks of $\alpha-\mathrm{MnO}_{2}$, further confirming the presence of $\alpha-\mathrm{MnO}_{2}$ in the composite (Fig. S5B $\dagger$ ). In the highresolution Fe $2 p$ XPS spectrum (Fig. S5C $\dagger$ ), the peaks of $\mathrm{Fe} 2 \mathrm{p}_{3 / 2}$ and $\mathrm{Fe} 2 \mathrm{p}_{1 / 2}$ at 710.6 and $724.1 \mathrm{eV}$ were the characteristic positions of $\mathrm{Fe}_{3} \mathrm{O}_{4},{ }^{36}$ indicating the existence of $\mathrm{Fe}_{3} \mathrm{O}_{4}$ nanoparticles in the $\mathrm{MnO}_{2}$ support. In the formation process of the GMFP nanocomposites, the initial GO was reduced to graphene, confirmed by significantly improving the intensity of $\mathrm{sp}^{2} \mathrm{C}-\mathrm{C}$ bonds of graphene and decreasing the oxygen containing carbon (epoxy $\mathrm{C}-\mathrm{O}$, carbonyl $\mathrm{C}=\mathrm{O}$, and carboxyl) (Fig. S5D $\dagger$ ). XPS spectra of the GMFP nanocomposites before and after adsorption of $\mathrm{Cr}(\mathrm{vI})$ were shown in Fig. S5E. $\dagger$ Before adsorption of $\mathrm{Cr}(\mathrm{vI})$, no $\mathrm{Cr}$ ions signals are observed in the XPS spectrum of GMFP. However, two energy bands at about 577.3 and $586.8 \mathrm{eV}$ appear after adsorption of $\mathrm{Cr}(\mathrm{vr})$, corresponding to the binding energies of $\mathrm{Cr} 2 \mathrm{p}_{3 / 2}$ and $\mathrm{Cr}$ $2 \mathrm{p}_{1 / 2}$. This observation suggests the existence of both $\mathrm{Cr}(\mathrm{III})$ and $\mathrm{Cr}(\mathrm{vI})$ on the surface of the GMFP after their adsorption of $\mathrm{Cr}(\mathrm{vI})$. The existence of $\mathrm{Cr}(\mathrm{vr})$ species on the surface of GMFP can be attributed to the adsorption of $\mathrm{Cr}(\mathrm{VI})$ ions through the anion exchange property of the surface of GMFP under acidic conditions. However, the appearance of $\mathrm{Cr}(\mathrm{III})$ on the surface of GMFP indicates that some fraction of adsorbed $\mathrm{Cr}(\mathrm{VI})$ was reduced to $\mathrm{Cr}(\mathrm{III})$ during the adsorption process. After treatment of $\mathrm{Cr}(\mathrm{vI})$, the $\mathrm{N} 1 \mathrm{~s}$ peak of GMFP shifted to a lower binding energy (Fig. S5F $\dagger$ ), and the peak width of $\mathrm{N}$ 1s decreased significantly, suggesting that the presence of positive nitrogen group in polypyrrole was regarded as a great contribution to the reduction process. ${ }^{37,38}$ There could be a possibility of reduction of $\mathrm{Cr}(\mathrm{vI})$ to $\mathrm{Cr}(\mathrm{III})$ in the presence of functional groups such as $-\mathrm{OH},-\mathrm{COOH}$, and $-\mathrm{NH}-$, on the surface of GMFP at low $\mathrm{pH}$ values due the occurrence of redox reactions between the surface groups and the $\mathrm{Cr}(\mathrm{vi})$. The whole process was represented by the following eqn and Scheme 3:

$$
\begin{gathered}
\mathrm{GMFP}+\mathrm{Cr}_{2} \mathrm{O}_{7}^{2-}+\mathrm{H}^{+} \rightarrow \mathrm{Cr}^{3+}+\mathrm{HCrO}_{4}^{-}+\mathrm{H}_{2} \mathrm{O} \\
\mathrm{HCrO}_{4}^{-}+7 \mathrm{H}^{+}+3 \mathrm{e} \rightarrow \mathrm{Cr}^{3+}+4 \mathrm{H}_{2} \mathrm{O}
\end{gathered}
$$

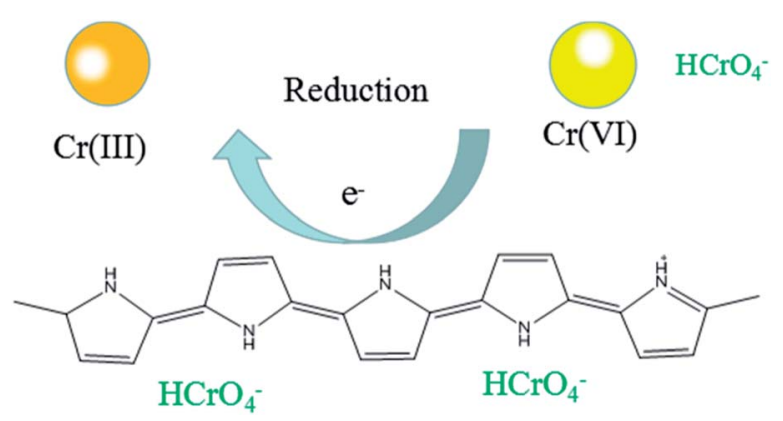

Scheme 3 Schemes illustrations of mechanism on the removal of $\operatorname{Cr}(v i)$.

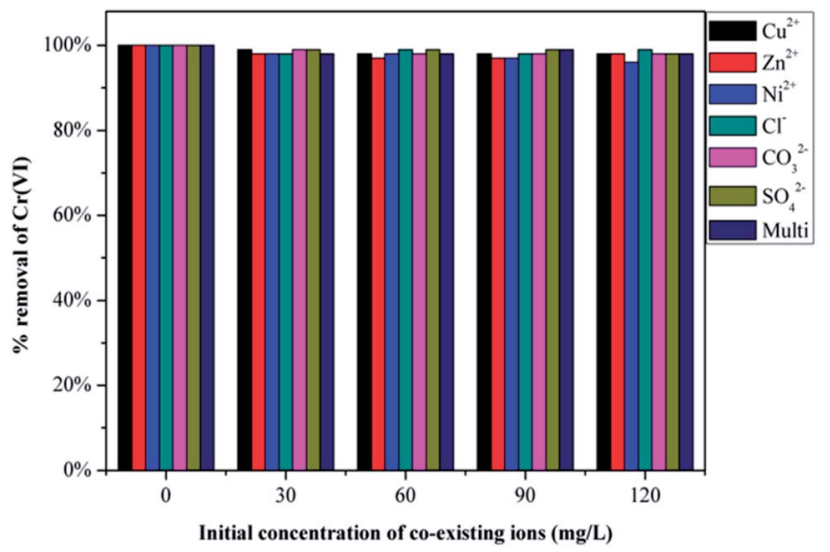

Fig. 8 Effect of co-existing ions on the removal of $\mathrm{Cr}(\mathrm{VI})$ by GMFP.

\subsection{Desorption performance of the GMFP}

For practical application, recycling and regeneration of the adsorbent is indispensable because the better repeated availability of advanced adsorbents may reduce the overall cost of the adsorbent. Given that the adsorption of $\mathrm{Cr}^{6+}$ ions onto the GMFP is pH-dependent and that the lower $\mathrm{pH}$ is beneficial for the $\mathrm{Cr}^{6+}$ adsorption, the desorption of $\mathrm{Cr}^{6+}$ ions from the adsorbent can be achieved by increasing the system $\mathrm{pH}$ values. Therefore, for the reusability study, experiments were conducted at alkaline condition. It can be seen that the GMFP nanocomposite still possessed more than $282 \mathrm{mg} \mathrm{g}^{-1}$ of the adsorption capacities for $\mathrm{Cr}^{6+}$ after four cycles of reuse, indicating that GMFP have a good reusability for $\mathrm{Cr}^{6+}$ adsorption, which slightly decreased to $264 \mathrm{mg} \mathrm{g}^{-1}$ at the fifth cycle, reflecting the high adsorption and stability of GMFP (Fig. S4†).

\subsection{Effect of co-existing ions}

Chromium-containing industrial wastewater also contains other types of particles, such as $\mathrm{Cu}^{2+}, \mathrm{Zn}^{2+}, \mathrm{Ni}^{2+}, \mathrm{Cl}^{-}, \mathrm{CO}_{3}{ }^{2-}$ and $\mathrm{SO}_{4}{ }^{2-}$. Therefore, it is essential to investigate the competitive influence of these co-existing ions on $\mathrm{Cr}(\mathrm{vI})$ removal and the results are presented in Fig. 8. Initially $\mathrm{Cr}(\mathrm{vI})$ removal was recorded using $50 \mathrm{~mL}$ of $200 \mathrm{mg} \mathrm{L}^{-1}$ of $\mathrm{Cr}(\mathrm{vI})$ solution and $30 \mathrm{mg}$ of GMFP. The figure shows that both anions and cations in solution at varying concentrations do not significantly affect the removal of $\mathrm{Cr}(\mathrm{vI})$ by GMFP. These results can be explained by the surface properties of GMFP. At low $\mathrm{pH}$, cations in solution are repelled from the positively charged surface of GMFP, and therefore, do not affect $\mathrm{Cr}(\mathrm{vI})$ removal. Anions such as $\mathrm{Cl}^{-}, \mathrm{CO}_{3}{ }^{2-}$ and $\mathrm{SO}_{4}{ }^{2-}$ are expected to compete with $\mathrm{Cr}(\mathrm{vI})$ because they are negatively charged $\left(\mathrm{HCrO}_{4}{ }^{-}\right)$. But it is not observed as seen from Fig. 8. One possible reason is that $\mathrm{Cl}^{-}, \mathrm{CO}_{3}{ }^{2-}$ and $\mathrm{SO}_{4}{ }^{2-}$ are weaker oxidising agents than $\mathrm{HCrO}_{4}{ }^{-}$, they are not reduced by GMFP and therefore do not affect $\mathrm{Cr}(\mathrm{vI})$ adsorption. ${ }^{33}$

\section{Conclusion}

Hexavalent chromium is one of the extremely toxic heavy metals of great concern in water supplies. Until now, different types of adsorbent materials have been widely studied for the removal of 
$\mathrm{Cr}(\mathrm{vI})$ from wastewater. However, conventional adsorbents often show a limited adsorption capacity or difficult to collected from wastewater, these shortages limit these materials in actual application. For conducting polymers, polypyrrole (PPy) has been studied for the removal of $\mathrm{Cr}(\mathrm{vI})$ from wastewater because of its tunable morphology, excellent redox property and longterm environment stability. In this study, we present a magnetic nanocomposite named GMFP, was fabricated based on $\mathrm{GO}, \mathrm{MnO}_{2}, \mathrm{Fe}_{3} \mathrm{O}_{4}$ and PPy, and it was confirmed by SEM, TEM, XRD, and FTIR. The $\mathrm{MnO}_{2} / \mathrm{PPy}$ composites with core/shell nanostructure were synthesized successfully via a simple approach, and performed excellently towards $\mathrm{Cr}$ (vi) adsorption in the aqueous solution, displaying high adsorption capacity (374.53 $\mathrm{mg} \mathrm{g}^{-1}$ ) under acidic conditions. The results of XPS shows the mechanisms of $\mathrm{Cr}$ removal, its suggested the adsorption effect was mainly because of the electrostatic attraction between the surface of the bare GMFP and $\mathrm{Cr}(\mathrm{vI})$, and the reduction from $\mathrm{Cr}(\mathrm{VI})$ to $\mathrm{Cr}(\mathrm{III})$ was mainly attributed to the functional groups (such as - $\mathrm{OH},-\mathrm{COOH}$, and - $\mathrm{NH}-$ ) of GMFP. This finding implicated that GMFP had great potential as an economical and efficient adsorbent of $\mathrm{Cr}(\mathrm{vI})$ from wastewater.

\section{Conflicts of interest}

There are no conflicts to declare.

\section{Acknowledgements}

This work was supported by the National Basic Research Program of China (2015CB932002), China-Singapore Joint Project (2015DFG92510), Science and Technology Service Network Initiative of Chinese Academy of China (KFJ-SW-STS172), and National Natural Science Foundation of China (No. 21371174, 21671052, 21375131 and 21475135).

\section{Notes and references}

1 M. K. Dinker and P. S. Kulkarni, J. Chem. Eng. Data, 2015, 60, 2521-2540.

2 F. Fu and Q. Wang, J. Environ. Manage., 2011, 92, 407-418.

3 Y. Sun, Q. Yue, Y. Mao, B. Gao and Y. Gao, J. Hazard. Mater., 2014, 265, 191-200.

4 X. Li, L. Ai and J. Jiang, Chem. Eng. J., 2016, 288, 789-797.

5 Y. Liu, C. Luo, G. Cui and S. Yan, $R S C A d v .$, 2015, 5, 5415654164.

6 A. Zhitkovich, Chem. Res. Toxicol., 2011, 24, 1617-1629.

7 V. Lugo-Lugo and B. Bilyeu, J. Hazard. Mater., 2012, 223, 112.

8 Y. Xing, X. Chen and D. Wang, Environ. Sci. Technol., 2007, 41, 1439-1443.

9 A. Sawada, K. Mori, S. Tanaka and M. Fukushima, Waste Manag., 2004, 24, 483-490.

10 V. K. Gupta, A. Nayak and S. Agarwal, Environmental Engineering Research, 2015, 20, 1-18.
11 H. Cui, M. Fu, S. Yu and M. K. Wang, J. Hazard. Mater., 2011, 186, 1625-1631.

12 J. Chen, X. Hong, Q. D. Xie and Q. F. Zhang, J. Chem. Eng. Data, 2014, 59, 2275-2282.

13 X. C. Ren and P. Wang, ACS Nano, 2012, 6, 2693-2703.

14 L. Fan, C. Luo, M. Sun and H. Qiu, J. Mater. Chem., 2012, 22, 24577-24583.

15 Z. Cheng, J. Liao, B. He and L. Zhou, ACS Sustainable Chem. Eng., 2015, 3, 1677-1685.

16 Y. Wu, H. Luo, H. Wang, C. Wang and J. Zhang, J. Colloid Interface Sci., 2013, 394, 183-191.

17 K. S. Subramanian, Anal. Chem., 1988, 60, 11-15.

18 R. Katal, M. Ghiass and H. Esfandian, J. Vinyl Addit. Technol., $2011,17,222-230$.

19 S. Li, X. Lu, X. Li, Y. Xue and J. Lei, J. Colloid Interface Sci., 2012, 378, 30-35.

20 M. Bhaumik, S. Agarwal, V. K. Gupta and A. Maity, J. Colloid Interface Sci., 2016, 470, 257-267.

21 J. Luo, H. J. Zhu, H. M. Fan, J. K. Liang, H. L. Shi and J. H. Rao, J. Phys. Chem. C, 2008, 112, 12594-12598.

22 D. Jampaiah, V. K. Velisoju, P. Venkataswamy, V. E. Coyle, A. Nafady, B. M. Reddy and S. K. Bhargava, ACS Appl. Mater. Interfaces, 2017, 9, 32652-32666.

23 Z. Liu, Y. Wang, R. Deng, L. Yang, S. Yu, S. Xu and W. Xu, ACS Appl. Mater. Interfaces, 2016, 8, 14160-14168.

24 L. Han, P. Tang and L. Zhang, Nano Energy, 2014, 7, 42-51. 25 K. Anupam, S. Dutta, C. Bhattacharjee and S. Datta, Chem. Eng. J., 2011, 173, 135-143.

26 S. C. Ponce, C. Prado, E. Pagano and F. E. Prado, Ecol. Eng., 2015, 74, 33-41.

27 J. H. Chen, K. C. Hsu and Y. M. Chang, Ind. Eng. Chem. Res., 2013, 52, 11685-11694.

28 K. Zhu, Y. Gao, X. L. Tian and C. L. Chen, ACS Sustainable Chem. Eng., 2016, 4, 4361-4369.

29 L. Fan, C. Luo, M. Sun and H. Qiu, J. Mater. Chem., 2012, 22, 24577-24583.

30 C. Luo, Z. Tian and B. Yang, Chem. Eng. J., 2013, 234, 256265.

31 T. Yao, T. Cui, J. Wu, Q. Chen, S. Lu and K. Sun, Polym. Chem., 2011, 2, 2893-2899.

32 M. Bhaumik, A. Maity, V. V. Srinivasu and M. S. Onyango, J. Hazard. Mater., 2011, 190, 381-390.

33 M. Bhaumik, S. Agarwal and V. K. Gupta, J. Colloid Interface Sci., 2016, 470, 257-267.

34 N. H. Kera, M. Bhaumik and N. Ballav, J. Colloid Interface Sci., 2016, 476, 144-157.

35 J. Chen, X. Hong and Q. Xie, J. Chem. Eng. Data, 2014, 59, 2275-2282.

36 T. Yamashita and P. Hayes, Appl. Surf. Sci., 2008, 254, 24412449.

37 S. H. Huang and D. H. Chen, J. Hazard. Mater., 2009, 163, 174-179.

38 N. H. Kera, M. Bhaumik, N. Ballav and S. S. Ray, J. Colloid Interface Sci., 2016, 476, 144-157. 